\title{
CHRONIC EXPERIMENTAL DIABETES MELLITUS; QUANTITATIVE CHANGES IN DORSAL ROOT GANGLION CELLS
}

1. Department of Human Anatomy, Faculty of Medicine, Umm al Qura University, Makkah, Saudi Arabia

2. Department of Human Anatomy, Faculty of Medicine, Umm al Qura University, Makkah, Saudi Arabia

3. Department of Pathology, Multan Medical and Dental College, Multan, Pakistan

Correspondence Address: Dr. Mohammad Afzal Khan Department of Human Anatomy,

Faculty of Medicine,

Umm al Qura University,

P.O. Box: 7607.

Makkah, Saudi Arabia

dr.khan1948@gmail.com

Article received on: 28/01/2015

Accepted for publication: 30/07/2015

Received after proof reading: $00 / 00 / 0000$

\section{Dr. Mohammad Afzal Khan', Dr. Faris Mohammed Nour Altaf ${ }^{2}$, Dr. Muhammad Naeem Chaudhry ${ }^{3}$}

ABSTRACT... Background: Multiple factors operate in the development of diabetic neuropathy. Sensory neurons are not protected by blood-brain or blood-nerve barrier; also the dorsal root ganglion cells (DRG) have a higher metabolic requirement than the nerve trunks. Oxygen level at the dorsal root ganglions also appears to be lower. All these physiological characteristics suggest that DRG may be particularly susceptible to damage in prolonged diabetic conditions. Objectives: To observe the quantitative cellular changes in dorsal root ganglion cells in rats with prolonged experimental diabetes. Study Design: An experimental study. Setting: Department of Human Anatomy, Faculty of Medicine, Umm al Qura University, Makkah, Saudi Arabia. Period: Fifteen months to complete. Material and methods: Observations were made on six control and six streptozotocin-treated male Sprague-Dawley rats after 12 months of diabetes. Cell count was done on silver-stained paraffin sections. DRG cells were arbitrarily grouped as large A-type and small B-type. Statistical examination of the cell count was done using a two-tailed t-test. Values were considered significant at $P \leq 0.05$. Results: In the control group of animals the mean total number was $15856.33 \pm 552.538$ while in the diabetic animals it was $11836.666 \pm 583.177$; the reduction in the number of cells was significant. The number of A-type and B-type cells and their percentages in the control group and the diabetic group of animals were $2753.833 \pm 257.683(17.36 \%), 13102.5 \pm 443.092(82.63 \%)$ and $1202.833 \pm 87.082$ $(10.16 \%), 10633.833 \pm 517.900(89.83 \%)$ respectively. The differences in the number of A-type and B-type of cells when compared between control and diabetic groups of animals were statistically highly significant. Conclusion: Selective cells damage to DRG cells may be the harbinger of diabetic neuropathy in experimentally induced diabetic rats.

Key words: Dorsal root ganglion cells, experimental diabetes mellitus, quantitative cellular change, diabetic neuropathy

Article Citation: Khan MA, Altaf FMN, Chaudhry MA. Chronic experimental diabetes mellitus; quantitative changes in dorsal root ganglion cells. Professional Med $\mathrm{J}$ 2015;22(12):1560-1564. DOI: 10.17957/TPMJ/15.2791

\section{INTRODUCTION}

The precise mechanism of diabetic neuropathy is not known; several pathophysiological mechanisms are psesent which ultimately result in increased oxidative stress, with deficits in nerve blood flow and sensory conduction'. Oxidative stress seems to be more intense at the dorsal root ganglion (DRG) as compared to at the nerve ${ }^{2}$. Recent findings that experimental diabetes beyond 6 months may develop florid radicular pathology in rats $^{3}$ coupled with observations of vacuolar type of degenerative changes of DRG neurons ${ }^{4}$ have lead to the hypothesis that the prime target in diabetic neuropathies is the sensory neuron. ${ }^{5}$
Sensory neurons are not protected by bloodbrain or blood-nerve barrier. ${ }^{6}$ Also the DRG have a higher metabolic requirement than the nerve trunks. ${ }^{7,8}$ Oxygen level at the dorsal root ganglions also appears to be lower ${ }^{9}$. All these physiological characteristics suggest that DRG may be particularly susceptible to diabetic microangiopathy.

It could be postulated, therefore, that direct targeting of the dorsal root ganglia could account for the early sensory neuropathy clinically observed in patients with diabetes mellitus.

The aim of the current study was to observe quantitative cellular changes in DRG cells in rats 
with prolonged experimental diabetes.

\section{MATERIALS AND METHODS}

\section{Animals}

Twelve male Sprague-Dawley rats, weighing $250 \pm 10 \mathrm{~g}$ were used. The animals were split in two groups of six animals each as control and experimental. Experimental diabetes was produced by an intraperitoneal injection of streptozotocin (STZ) $0.05 \mathrm{~mol} / \mathrm{l}$ with citrate buffer and with a pH 4.5. Citrate buffer alone was administered intra-peritonealy to the control group. Ad libitum access to rodent laboratory chow and water was available to both the control and the diabetic animals. The rats were considered as diabetic if their fasting blood glucose level exceeded $16.7 \mathrm{mmol} / \mathrm{l}$ three days after injection of STZ and remained at this level till the time of surgery. The duration of experimental diabetes was twelve months for the diabetic rats.

\section{Histological preparation}

Experimental and control animals were given pentobarbital sodium $50 \mathrm{mg} / \mathrm{kg}$ by intraperitoneal injection for anesthesia. Laminectomy was then done and the lumbar-5 dorsal root ganglia were exposed and fixed by formaldehyde in place for 20 min. Lumber-5 DRG were then harvested, post fixed in $10 \%$ formaldehyde overnight, and processed for paraffin embedding. Four to six micron thick transverse sections were stained with silver nitrate.

\section{Cell count}

Serial sections were initially observed and compared at $10^{\text {th }}, 20^{\text {th }}, 30^{\text {th }}, 40^{\text {th }}$ and $50^{\text {th }}$ section for the cell counts and diameter. In all these samples there was no significant difference in cell counts or their diameters. Therefore subsequent analysis was done using every $30^{\text {th }}$ section which was found to be at the largest diameter of DRG.

Cells were counted at 20x magnification for all selected specimens. For the cell size, measurement of the largest diameter was made only on those cells which showed the nucleolus or part of the nucleolus. The cell count was corrected by multiplying with a correction factor to make up for the split nucleoli. , $^{9}$

Early observations revealed differences in the size of the DRG cells which were arbitrarily divided in two groups: those larger than 1500 micron $^{2}$ were named 'A-type' and those smaller than 1500 micron ${ }^{2}$ were termed as 'B-type'.

\section{Statistics}

Total cell counts, large (A-type) and small (B-type) populations, were expressed as means \pm SE. Two-tailed t-test was used for comparisons. Significance was accepted at $P \leq 0.05$.

\section{RESULTS}

The weight of animals was reduced significantly $(287 \pm 23 \mathrm{~g})$ as compared with the controls $(532 \pm 33 \mathrm{~g})$ at the time of surgery after 12 months $(P \leq 0.01)$. Fasting glucose level for the diabetic rats was $16.4 \pm 4.2 \mathrm{mmol} / \mathrm{l}$ at the time of surgery.

The number and percentages of A-type (large) and B-type (small) DRG cells in the control and experimental groups are shown in Table I.

In the control group of animals the mean total number was $15856.33 \pm 552.538$ while in the diabetic animals it was $11836.666 \pm 583.177$; the decrease in the total number of cells was found to be significant (Table II). Similarly the number of A-type and B-type cells and their percentages in the control and diabetic animals were $2753.833 \pm 257.683$ (17.36\%), $13102.5 \pm 443.092$ $(82.63 \%)$ and $1202.833 \pm 87.082$ (10.16\%), $10633.833 \pm 517.900$ (89.83\%) respectively. The differences in the number of A-type and B-type of cells when compared between control and diabetic groups of animals were statistically highly significant (Table II).

\section{DISCUSSION}

Weight loss observed in the experimental group of animals was expected and is in agreement with previous observations on STZ-induced diabetic rats. ${ }^{14,17}$ It appears that our method of sampling, profile counting and application of correction factors was satisfactory for cell counting. Our 


\begin{tabular}{|c|c|c|c|c|c|}
\hline \multirow{2}{*}{ Animals } & \multicolumn{3}{|c|}{ Number of cells } & \multicolumn{2}{|c|}{ Percentage } \\
\hline & Total & A-type & B-type & A-type & B-type \\
\hline \multicolumn{6}{|l|}{ Control: } \\
\hline C-1 & 16542 & 2991 & 13551 & $18.08 \%$ & $81.91 \%$ \\
\hline C-2 & 14356 & 1681 & 12675 & $11.70 \%$ & $88.29 \%$ \\
\hline C-3 & 17765 & 2778 & 14987 & $15.63 \%$ & $84.36 \%$ \\
\hline C-4 & 15490 & 2837 & 12653 & $18.31 \%$ & $81.68 \%$ \\
\hline C-5 & 14398 & 2612 & 11786 & $18.14 \%$ & $81.85 \%$ \\
\hline C-6 & 16587 & 3624 & 12963 & $21.84 \%$ & $78.15 \%$ \\
\hline Mean \pm SE & $15856.333 \pm 552.538$ & $2753.833 \pm 257.683$ & $13102.5 \pm 443.092$ & $17.36 \%$ & $82.63 \%$ \\
\hline \multicolumn{6}{|l|}{ Experimental: } \\
\hline D-1 & 12654 & 1178 & 11476 & $9.30 \%$ & $90.69 \%$ \\
\hline D-2 & 10654 & 1122 & 9532 & $10.53 \%$ & $89.46 \%$ \\
\hline D-3 & 9896 & 920 & 8976 & $9.29 \%$ & $90.70 \%$ \\
\hline D-4 & 11475 & 1111 & 10364 & $9.68 \%$ & $90.31 \%$ \\
\hline D-5 & 13754 & 1352 & 12402 & $9.82 \%$ & 90.17 \\
\hline D-6 & 12587 & 1534 & 11053 & $12.18 \%$ & $87.81 \%$ \\
\hline Mean $\pm S E$ & $11836.666 \pm 583.177$ & $1202.833 \pm 87.08$ & $10633.833 \pm$ & $10.16 \%$ & 89.8 \\
\hline
\end{tabular}

Table-I. Showing the number and percentages of A-type (large) and B-type (small) DRG cells in the control and experimental groups

\begin{tabular}{|c|c|c|c|c|c|}
\hline \multicolumn{2}{|c|}{ Total cells } & \multicolumn{2}{c}{ A-type cells } & \multicolumn{2}{c|}{ B-type cells } \\
\hline $\mathrm{t}$-value & $\mathrm{p}$-value & $\mathrm{t}$-value & $\mathrm{p}$-value & $\mathrm{t}$-value & $\mathrm{p}$-value \\
\hline 5.003539 & $0.000267^{\star}$ & 5.702196 & $9.900005^{\star}$ & 3.621975 & $0.00237^{\star}$ \\
\hline
\end{tabular}

Table-Il. Showing the statistical comparison of cell count between the control and experimental groups' $t-$ and pvalues and their significance after t-test

*significant at $p<0.05$.

cell count in the control group of animals was in general agreement with previous studies using similar methods. ${ }^{11,12}$ Whereas our mean values for the total DRG cell count were $15856.33 \pm$ 552.538 literature reports a range of thirteen thousand to eighteen thousand. ${ }^{11-13}$ These reports by other investigators validate and support our methodology and observations.

The cut-off line between the large and small cells was 1500 micron $^{2}$ (with a maximal diameter of 20 microns); so that the DRG cells were arbitrarily classified into two groups: those larger than 1500 micron $^{2}$ were named ' $A$ ' and those smaller than 1500 micron $^{2}$ were termed as ' $B$ '. The small B-type cells had a diameter much smaller than 20 microns.

We report a decrease in the number of A-type cells and a relative increase in percentage of B-type cells in the diabetic animals which is in agreement with previous workers. ${ }^{4,10}$ Our observations are different from those reported by Sidenius and Jakobsen ${ }^{14}$ in short-term streptozotocin-induced diabetes in rats. Eighteen per cent reduction in cell volume affecting neurons of all sizes is reported by these authors. Our observations strongly indicate a loss that was confined to the large cell population rather than an even reduction as seen in case of atrophy. It seems plausible that the damage in our study appears to be selective rather than general as proposed by Sidenius and Jakobsen. ${ }^{14}$ Also the duration in our study was twelve months as compared to four months by these authors. The effects of diabetic conditions therefore are not comparable. The increase in percentage of the small B-type cells in the diabetic group is only relative to the 
decrease of the large cells.

Correlations between electrophysiological characteristics and properties of the neurons and their axonal processes with the size of the DRG cells have been made in the rat and cat. ${ }^{15,16}$ The small (type B) neurons are mostly connected to unmyelinated nerve fibers, only a few being connected to the small myelinated fibers. ${ }^{16}$ The large (type A) neurons are connected to thick myelinated fibers and belong to the A-alph and A-beta type of fibers. There is a linear relationship between the size of the neuron and the velocity of conduction by the axon. ${ }^{15,16}$ It is reported that changes following loss of neurons are associated with changes in both the dorsal and the ventral nerve roots indicated by demyelination of nerve fibers. ${ }^{3,17}$

That these changes are functionally important has been shown by electrophysiological observations. ${ }^{18,19}$ In our study we have observed a loss of A-type cells in the DRG whereas the B-type cells remained unaffected indicating therefore that loss of cells appears to be selective rather than general.

Motor and autonomic fibers are also affected in experimental diabetes ${ }^{20}$ and therefore DRG neurons should be considered as only one target. It needs to be considered if the sensory, motor and autonomic nerve fibers are also involved along with their parent cells in longstanding diabetes.

\section{CONCLUSION}

Decrease in A-type cells in our study indicates a selective damage to the dorsal root ganglion cells in prolonged experimentally induced diabetes mellitus in rats and may be the harbinger of diabetic neuropathy. However further studies to elucidate specific nerve fiber involvement and changes therein are warranted.

Copyright@ 30 July, 2015.

\section{REFERENCES}

1. Low PA: Pathogenesis of diabetic neuropathy. In Joslin's Diabetes Mellitus. Kahn CR, Weir GC, King GL, Moses AC, Jacobson AM, Smith RJ, Eds. Philadelphia, Lippincott Williams \& Wilkins, 2008.
2. Nickander KK, Schmelzer JD, Rohwer DA, Low PA: Effect of -tocopherol deficiency on indices of oxidative stress in normal and diabetic peripheral nerve. J Neurol Sci 1994; 126:6-14.

3. Tamura E, Parry GJ: Severe radicular pathology in rats with longstanding diabetes. J Neurol Sci 1994; 127:29-35.

4. Sasaki H, Schmelzer JD, Zollman PJ, Low PA: Neuropathology and blood flow of nerve, spinal roots and dorsal root ganglia in longstanding diabetic rats. Acta Neuropathol 1997; 93:118-128.

5. Low PA, Lagerlund TD, McManis PG: Nerve blood flow and oxygen delivery in normal, diabetic, and ischemic neuropathy. Int Rev Neurobiol 1989; 31:355438.

6. Arvidson B. Distribution of protein tracers in peripheral ganglia: a light and electron microscopic study in rodents after various modes of tracer administration. Acta Univ Upps 1979;344:1-72.

7. Greene DA, Winegard Al, Carpentier JL, Brown MJ, Fukuma M, Orci L. Rabbit sciatic nerve fascicle and endoneurial preparations for in vitro studies of peripheral nerve glucose metabolism. J Neurochem 1979; 33:1007-18

8. Kadekaro M, Crane AM, Sokoloff L. Differential effects of electrical stimulation of sciatic nerve on metabolic activity in spinal cord and dorsal root ganglion in the rat. Proc Nat Acad Sci USA 1985; 82:6010-13

9. Zochodne DW, Ho LT. Unique microvascular characteristics of the dorsal root ganglion in the rat. Brain Res 1991; 559:89-9

10. Kishi M, Mitsui M, Nagamatsu M, Nickander KK, Schmelzer JD, Tanabe J,Yao JK, Low PA: Dorsal root ganglion pathology in chronic experimental diabetic neuropathy. J Peripher Nerv Syst. 2001; 6:152A-153A,

11. Tandrup T: A method for unbiased and efficient estimation of number and mean volume of specified neuron subtypes in rat dorsal root ganglion. J Comp Neurol. 1993; 329:269-276.

12. La Forte RA, Melville S, Chung K, Coggeshall RE: Absence of neurogenesis of adult rat dorsal root ganglion cells. Somatosens Mot Res. 1991; 8:3-7.

13. Pover CM, Barnes MC, Coggeshall RE: Do primary afferent cell numbers change ii relation to increasing weight and surface area in adult rats? Somatosens Mot Res. 1994; 11:163-167.

14. Sidenius $P$, Jakobsen J: Reduced perikaryal volume 
of lower motor and primary sensory neuron in early experimental diabetes. Diabetes1980; 29:182-186.

15. Lee $\mathrm{KH}$, Chung $\mathrm{K}$, Chung JM, Coggeshall RE: Correlation of cell body size, axon size, and signal conduction velocity for individually labelled dorsal root ganglion cells in the cat. J Comp Neurol. 1986; 243:335-346.

16. Harper $A A$, Lawson $S N$ : Conduction velocity is related to morphological cell type in rat dorsal root ganglion neurones. J Physiol 1985; 359:31-46.

17. Srinivasan S, Stevens M, Wiley JW: Diabetic peripheral neuropathy: evidence for apoptosis and associated mitochondrial dysfunction. Diabetes 2000; 49:19321938.
18. Kishi M, Mitsui M, Nagamatsu M, Nickander KK, Schmelzer JD, Tanabe J, Yao JK, Low PA: Dorsal root ganglion pathology in chronic experimental diabetic neuropathy. J Peripher Nerv Syst. 2001; 6:152A-153A.

19. Harper $A A$, Lawson $S N$ : Conduction velocity is related to morphological cell type in rat dorsal root ganglion neurones. J Physiol. 1985; 359:31-46.

20. Nagamatsu M, Nickander KK, Schmelzer JD, Raya A, Wittrock DA, Tritschler H, Low PA: Lipoic acid improves nerve blood flow, reduces oxidative stress, and improves distal nerve conduction in experimental diabetic neuropathy. Diabetes Care. 1995; 18:11601167.

\section{"There is only one way to avoid criticism. do nothing say nothing and be nothing."}

\section{Aristotle}

\section{AUTHORSHIP AND CONTRIBUTION DECLARATION}

\begin{tabular}{|c|r|}
\hline Sr. \# & Author-s Full Name \\
1 & Mohammad Afzal Khan \\
2 & Faris M. Nour Altaf \\
3 & M. Naeem Chaudhary
\end{tabular}

Contribution to the paper

All authors contributed equally and extensivel to the work presented in this paper

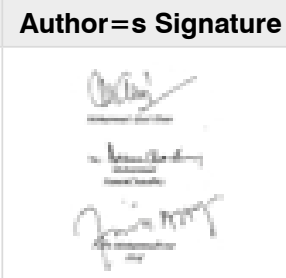

